\title{
PLAYING WITH PARETTO: UMA PROPOSTA LÚDICA PARA A PRÁTICA DA CLASSIFICAÇÃO ABC
}

\author{
Giselly de Medeiros Santos da Silva (Instituto Federal do Rio Grande do Norte) \\ gisellymssilva2@gmail.com \\ Maria Eduarda Correia Pedrosa (Instituto Federal do Rio Grande do Norte) \\ eduardapedrosamecp@gmail.com \\ Alice Beatriz Pimenta Oliveira de Sá (Instituto Federal do Rio Grande do Norte) \\ alice.beatriz.pimentta@gmail.com \\ Marcus Vinicius Dantas de Assunção (Instituto Federal do Rio Grande do Norte) \\ marcus.assuncao@ifrn.edu.br
}

\section{Resumo}

As incessantes transformações no cenário tecnocrático mundial fomentam a adesão da praticidade como fundamento para o desenvolvimento das instancias tecnológicas, cada vez mais assíduos no processo de ensino aprendizagem devido aos resultados da integração dos mercados na sociedade. Para tanto, métodos lúdicos como os jogos simuladores, tornam-se um mecanismo indispensável no procedimento de estímulo a qualificação de profissionais em setores como a logística, pois objetiva a rápida compreensão de teorias por meio da prática. Posto a finalidade estratégica dos jogos simuladores no campo educacional, o presente artigo tem o propósito preconizar o jogo acadêmico Playing With Paretto, que ao abordar conhecimentos de gestão de estoques, destinando-se a estudantes na área de logística e engenharia de produção. $\mathrm{O}$ jogo em questão se caracteriza como de tabuleiro e sua objeção é o desenvolvimento de uma classificação $\mathrm{ABC}$, determinados por critérios estabelecidos por cartas (produtos e limites).

Palavras-Chaves: Jogos em Logística, Jogos Acadêmicos, Curva ABC.

\section{Introdução}

As passíveis e constantes transformações sociais, culturais e mercadológicas em que a sociedade está introduzida, exige um campo intenso de busca de conhecimento e qualificação profissional devido a rigidez do mercado de trabalho. Essa competência desenvolve expectativas quanto à estruturação de métodos eficientes habilitados a suprir as necessidades da população e dos setores empresariais, os quais estão inseridos tecnocracia competitiva e carecem de métodos de aprendizagem dinâmicos e produtivos. 
Com o intuito de potencializar os processos de ensino aprendizagem e atender as exigências do mercado, cada vez mais participativo nas temáticas educacionais, os jogos simuladores apresentam-se como instrumentos hábeis na integração da teoria com a prática, sendo ainda uma estratégia no processo de difusão de áreas marcados pela baixa qualificação profissional. Visto que esses jogos buscam, em curto período, retratar de modo didático a complexa realidade das empresas e, dessa forma, assumir a função de agente direto no processo de ensino aprendizagem dos indivíduos.

De acordo com Bernard (2006) a simulação, como metodologia de ensino, centraliza a aprendizagem nos problemas apresentados ao estudante que analisa as possibilidades que podem ser adotadas e decide qual utilizar para resolução do problema em foco, responsabilizando-se em grande parte pelo seu próprio ensino. A simulação traz situações do cotidiano de uma organização e/ou do mercado em que se está inserida, desta forma os estudantes, com base em informações que lhes são repassadas, tomam decisões em condições próximas aos reais.

Diante da carência de profissionais capacitados na Logística, bem como o limitado conjunto de ferramentas dinâmicas e flexíveis a serem aplicadas no processo de ensino aprendizagem, o presente artigo tem como objetivo propor um jogo de cunho acadêmico voltado para elaboração do método de gestão de estoques conhecido como curva $\mathrm{ABC}$, visando colaborar com o desenvolvimento da área.

\section{Referencial teórico}

\subsection{Logística}

Ballou (2009), afirma que a função da logística é mais ampla e não corresponde a apenas ao método de planejamento, adesão e domínio do fluxo eficaz e eficiente de produtos, serviços e informações que se referem ao processo desde o ponto de princípio (produção) até o término (consumo). Além de suprir as imposições do mercado consumidor, a logística configura-se como um aglomerado de práticas funcionais como os transportes, controle de estoque, almoxarifado, dentre outras atividades, que são reproduzidas inúmeras vezes ao longo do canal pelo qual matérias-primas vão sendo transformado em produtos acabados, aos quais se agregam valor ao consumidor.

A logística ergue-se numa conjuntura militar executando algumas atividades como o abastecimento, manutenção, transporte, evacuação e hospitalização de feridos e serviços conexos (Carvalho; Cardoso, 2002). Perante os empecilhos encontrados no decorrer dos 
combates tornava-se necessário determinar algumas deliberações importantes para o progresso das guerras, como podemos mencionar a análise dos melhores e mais eficazes procedimentos para a conservação dos alimentos e transportes e como estabelecer a quantidade de alimentos e armas necessárias. Devido esses acontecimentos, a logística demonstrou-se um significativo direcionador estratégico tanto no contexto militar como em outras circunstâncias.

A maior rede global de profissionais especializados na Gestão da Cadeia de Suprimentos o Council of Supply Chain Management Professionals (CSCMP, 2013) define a Logística ou Gestão Logística como a parte da Cadeia de Abastecimento que é responsável por planejar, programar e controlar o eficiente e eficaz fluxo direto e inverso e as operações de armazenagem de bens, serviços e informação relacionada entre o ponto de origem e o ponto de consumo, de forma a ir ao encontro dos requisitos/necessidades dos clientes., buscando suprir as necessidades dos clientes. Nota-se que a importância da logística vai além do âmbito da gestão empregada às organizações, ela está intrínseca também na administração operacional de atividades cotidianas.

Consoante a isso, a maior rede global de profissionais especializados na Gestão da Cadeia de Suprimentos o Council of Supply Chain Management Professionals (CSCMP, 2013) estabelece a logística ou Gestão logística como membro da Cadeia de Abastecimento que possui a responsabilidade de planejar, controlar e programar de forma eficiente e eficaz o fluxo direto e inverso e as operações de armazenagem de bens, serviços e informação relacionada entre o ponto de origem e o ponto de consumo, de forma a ir ao encontro dos requisitos/necessidades dos consumidores finais buscando atender as necessidades desejadas. Frente a essa perspectiva, é notória a importância da logística e como ela se faz presente tanto em organizações quanto em exercícios cotidianos e na administração operacional.

\subsection{Curva ABC}

A curva ABC, curva de Paretto ou curva 80 - 20, foi proposta por Vilfredo Paretto ainda no século XIX, por meio de um estudo de renda. A lógica utilizada por este renascentista italiano seria de que a distribuição de renda se dava por meio desuniforme, em que $20 \%$ da população detinha $80 \%$ das riquezas e os outros $80 \%$ possuíam apenas $20 \%$ dessa mesma riqueza. Este princípio de análise tornou-se uma técnica de gestão após Joseph Juran estabelecer uma relação de causa e consequência quando sugeriu que $80 \%$ dos problemas de uma Organização são resultantes de apenas $20 \%$ das causas. 
Stoner et al. (1999) ressalta a eficácia dessa associação quando cita a Pacific Bell como beneficiada com a aplicação desse método que segundo este autor, no momento em que a empresa tentava encontrar um meio de reduzir os danos aos cabos telefônicos subterrâneos, descobriu-se, por meio desse diagrama, a principal causa dos defeitos da telefonia. A análise revelou que $41 \%$ dos danos nos cabos eram devidos aos trabalhos de construção. Tendo essa informação à disposição, a Pacific Bell desenvolveu um plano de reduzir os cortes de cabos em $24 \%$ em um ano, conseguindo economizar US\$6 milhões.

Deve-se ter em mente ainda que, apesar da análise $\mathrm{ABC}$ ser meritoriamente aplicada mediante o valor de consumo por período, este é apenas um dos muitos critérios que pode afetar a classificação de um item. A adoção desse esquema de classificação se justifica por aspectos gerenciais, uma vez que ao reconhecer as influências de determinados critérios a um certo elemento, quer sejam estas de características industriais, comerciais ou de prestação de serviços, o desenvolvimento de táticas de controle torna-se mais eficiente.

Apesar de ser mais implementado na área de Gestão de Estoques, possui um grande potencial para atuar como fator decisivo na qualidade de serviço, definida por Deming (1986) como uma arma para a vantagem competitiva. Sendo assim, uma análise $\mathrm{ABC}$ deve obrigatoriamente refletir a dificuldade de controle e impacto dos elementos envolvidos sobre os custos e a rentabilidade das operações.

Após a importância relativa aos critérios adotadas dos materiais ou operações serem identificadas, as classificações dentro das classes $\mathrm{ABC}$ podem ser realizadas. As definições das classes ABC conceituadas por Laugeni et al. (2015) estão dispostas na Figura 1.

Figura 1 - Classificação ABC

Classe A

Corresponde a pouca representatividade no processo geral ou em itens (cerca de $10 \%$ ou $20 \%$ dos itens);

O valor de consumo acumulado ou impacto na operação final é alto (acima de $50 \%$ até $80 \%$ ).
Classe B

Classe C
Formada por uma representatividade média no processo geral ou em itens ( $20 \%$ a $30 \%)$; O valor acumulado ou impacto na operação final é em tomo de de $20 \%$ a $30 \%$.
Corresponde a um grande representatividade no processo geral ou em número de itens (acima de $50 \%$ );

O valor de consumo acumulado ou impacto na operação final é baixo (5\% a $10 \%$ )

\subsection{Educação x Logística}


A Educação sendo um campo oscilante, devido a sua imersão nos contextos sociais, veio a tornar-se elemento-foco em muitas áreas de pesquisa que contemplam o setor operacional, como Administração, Economia, Engenharia, entre outros. Para Gaither; Frazier, 2002; Fleury, 2000, a justificativa para este fato encontra-se no presente mercado, os autores citam o acúmulo desses conhecimentos associados ao meio técnico-científico como elemento de estratégia para a Organização, pois no contexto vigente, o poder está nas mãos daqueles que gerenciam o conhecimento e não dos que propriamente fazem uso dele, em função de sua dependência dos primeiros.

Como forma de nutrir a conjuntura vigente de forma ampla, novas ferramentas estão sendo desenvolvidas com o objetivo de potencializar setores que apesar de relevantes em contexto internacional, são prejudicadas, seja por falta de conhecimento ou reconhecimento. Os jogos compõem o grupo de métodos cada vez mais explorados pelos educadores, pois de acordo com Borges (1999), pode promover um aprendizado mais significativo, desenvolvendo a motivação do aluno na construção de novos conhecimentos.

Em concordância a isso, Miyashita (1997) insere ainda dentre os benefícios da prática dos jogos no âmbito educacional, a economia de tempo para absorção de grandes quantidades de conceitos. Este fato ampara a teoria de Adamo-Villani, Haley-Hermiz e Cutler (2013) de que mecanismos dinâmicos de aprendizagem podem contribuir com uma situação recorrente, principalmente em cursos de áreas tecnológicas, as altas taxas de evasão e desistência.

\subsection{Jogos em Logística}

Bernand (2006) atenta-se a característica dos jogos de pôr o estudante como responsável pela maior parte da sua aprendizagem, uma vez que a simulação, como metodologia de ensino, centraliza a aprendizagem nos problemas apresentados ao indivíduo, que analisa as possibilidades que podem ser adotadas e decide qual utilizar para resolução do problema em foco. Além do mais, o indivíduo aprende as consequências das suas decisões sem necessariamente sofre-las. Diante das necessidades existentes no cenário logístico brasileiro, a área carece de profissionais capacitados para exercer a habilidade do diagnóstico, além disso, ser capaz de propor um modelo de melhoria. Os jogos simuladores tronam-se ferramenta estratégica para difundir conceitos e práticas em curto período.

Segundo Ornellas apud Campos (2003), isso permite, teoricamente, errar e voltar atrás em um mercado competitivo que pune cada vez mais severamente os erros cometidos. 
Os jogos buscam retratar de forma a realidade das empresas, delimitando algumas variáveis trabalhadas e restringindo o impacto de outras no modelo. Dessa forma, procuram simular o ambiente empresarial, colocando os jogadores diante de situações símile àquelas vivenciadas pelos executivos em sua rotina de trabalho. São métodos alternativos de treinamento de executivos e possuem algumas vantagens em relação aos métodos tradicionais, como o treinamento no exercício de um cargo específico. Usualmente, os jogos auxiliam no processo de ensino-aprendizagem dos empregados, possibilitam maior integração entre as pessoas incitando a colaboração em equipe e são muito mais econômicos no tempo de aprendizado, pois em pequeno espaço de tempo conseguem transmitir uma grande quantidade de conceitos. Além disso, possuem a vantagem de não comprometer a operação normal da empresa, uma vez que são realizados geralmente em um ambiente independente e isolado (CARLSON; MISSHAUK, 1972; KOPITTKE，1989; MIYASHITA，1997; SCHAFRANSKI，2002; ROSAS; SAUAIA, 2006; ARCANJO; CARVALHO; VIEIRA, 2009).

\section{Metodologia}

O desenvolvimento do Playing With Paretto se deu a partir de 4 estágios, quais sejam: (I) Pesquisa bibliográfica aspirando apropriação na temática, (II) Definição da atividade logística ao qual o jogo será voltado, (III) Construção do contexto lúdico, definição de metas e objetivos, (IV) Revisão geral da prática desenvolvida. A Figura 1 representa de forma ilustrativa essas etapas metodológicas da pesquisa.

Figura 2 - Etapas metodológicas da pesquisa 
I- Pesquisa bibliogrấca visando

dominio na temática
II- Definição da atividade

logistica ao qual o jogo será

voltado

Nesta etapa fez-se um levantamento dos jogos logísticos já existentes e observou-se que a maioria deles são voltados para a área empresarial, buscando inserir um jogo na área acadêmica, que apresentasse dinamização e que chamasse a atenção dos alunos para a sua prática.
Em detrimento da carência de abordagens lúdicas das atividades de gestão de estoques, decidiu-se elaborar um jogo que aborde aspectos da classificação $\mathrm{ABC}$
III- Construção do contexto lúdico, definição de metas e objetivos
IV- Revisão geral da prática desenvolvida
Definiu-se como principal objeção despertar no discente a interpretação das que as classificações $A B C$ proporcionam nas atividades logísticas.
As aplicações do jogo foram testadas com o objetivo de atingir os resultados esperados.

Fonte: Autores (2019)

O jogo em evidência foi elaborado no ano de 2019, em função da carência na área logística de técnicas lúdicas de ensino-aprendizagem e capacitação profissional, possuindo como tema a elaboração a elaboração de uma curva abc (método utilizado na gestão de estoques) visto a sua relevância para o aprimoramento de processos.

Os documentos estudados para composição do presente artigo estão inseridos em um recorte temporal de 1972 até o ano de 2019.

\section{Resultados e discussões}

Diante do binômio carência do setor logístico x benefícios da prática dos jogos no processo de ensino aprendizagem, foi desenvolvido um jogo de caráter acadêmico a fim de provocar no discente o interesse quanto às possiblidades acerca da utilização das classificações $A B C$ no contexto da Logística, assim como alavancar a capacidade técnica do indivíduo. O jogo caracteriza-se como um jogo de tabuleiro, e é recomendado que sua realização seja em grupo, a fim de maximizar as vantagens que o jogo oferece. A descrição geral do jogo desenvolvido está presente na Tabela 1.

Tabela 1 - Descrição geral do jogo 
ordenado

\begin{tabular}{ll}
\hline PÚBLICO ALVO & Estudantes na área de Engenharia de Produção e Logística \\
\hline CONHECIMENTOS & Gestão de Estoque, Fundamentos de Logística \\
ABORDADOS & Tabuleiro \\
\hline TIPO & T \\
\hline
\end{tabular}

Fonte: Autores (2019)

\subsection{Descrição do jogo}

Playing with Paretto é um jogo de enfoque acadêmico direcionado às áreas de Engenharia de Produção e Logística que objetiva unificar a teoria da classificação ABC ou 80-20 com algumas possibilidades de aplicações, portanto, a meta do jogo é a elaboração de uma curva abc ou abcd de acordo com o critério imposto pela roleta que será girada por um representante da cada grupo. Os dados para essa construção estarão presentes em cada uma das 6 cartas que serão distribuídas a cada grupo. Essas cartas conterão no total 4 informações (o valor do produto, a demanda, o giro de estoque e o ciclo de vida), no entanto, só deve ser utilizado o critério atribuído pela carta-surpresa. O limite de uma classe para outra classe será orientado pela carta-limite entregue uma para grupo, só deverá ser usado o limite referente ao critério solicitado.

\subsection{O jogo suas pontuações e penalidades}

O Jogo não possui penalidades e regra única de realizar todo andamento do jogo sem nenhum tipo de consulta ( livro, atividades, artigos, entre outros) sobre o assunto de curva ABC. Deverá ser atribuída a prática do jogo uma pontuação definida pelo aplicador e para a pontuação será levado em consideração o tempo da prática e se a curva $\mathrm{ABC}$ foi feita corretamente.

\subsection{Prática}

O jogo poderá ser praticado individualmente ou em grupos de no máximo 6 alunos cada, para cada jogador ou equipe deverão ser entregues um tabuleiro similar o da figura 3 , uma carta limite, referente a figura 4 e cartas produtos, referente a figura 5. A quantidade de cartas deverá ser limitada pelo professor ou alguém que irá orientar o jogo. O tabuleiro deve conter um espaço identificado com um ponto de interrogação (?), esse espaço está designado para por as cartas produtos que serão escolhidas ao acaso por cada jogador ou equipe no inicio do 
jogo, os espaços identificados com as letras A,B,C e D são para por as cartas produtos em sua respectiva classe ( ex: produtos de classe A no espaço A) no decorrer da prática, o plano cartesiano servirá para que o jogador ou equipe monte sua curva $\mathrm{ABC}$ referente aos produtos escolhidos e a roleta posicionada logo abaixo do plano cartesiano servirá para que cada jogador ou equipe tenha um parâmetro escolhido pela sorte, são os possíveis parâmetros: Preço, Ciclo de vida e Rotatividade. Cada carta produto deverá conter uma breve descrição do produto seguido do seu preço, rotatividade e ciclo de vida. Cada carta limite deverá conter um limite único para cada parâmetro que será utilizado nos cálculos da curva $\mathrm{ABC}$. No total devem estar disponíveis 6 tabuleiros, 30 cartas produtos e 6 cartas limites.

Figura 3 - Tabuleiro.

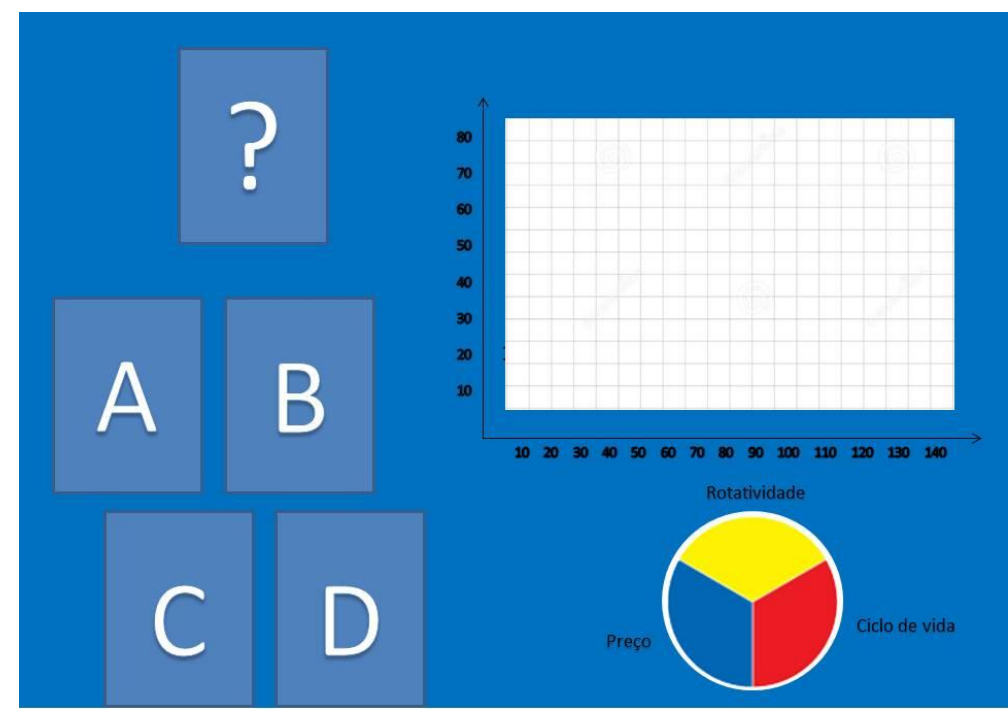

Fonte: Autores (2019).

Figura 4 - Carta limite
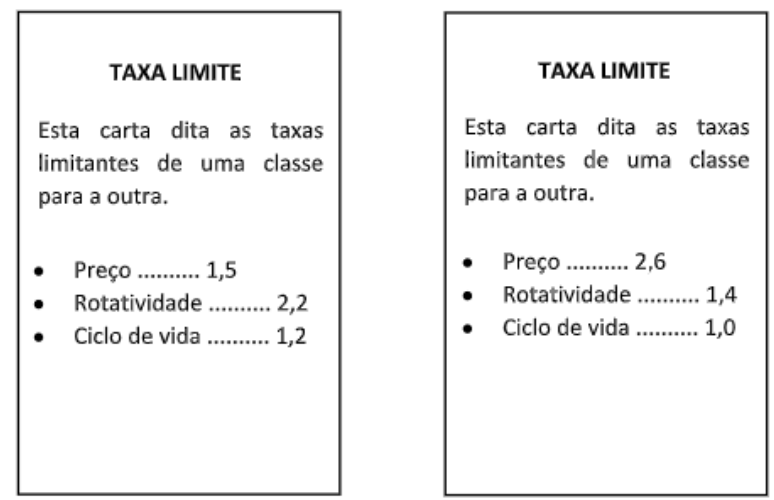

TAXA LIMITE

Esta carta dita as taxas limitantes de uma classe para a outra.

- Preço ........... 1,2

- Rotatividade ........... 1,7

- Ciclo de vida ........... 1,9

Fonte: Autores (2019). 
Figura 5 - Carta produto
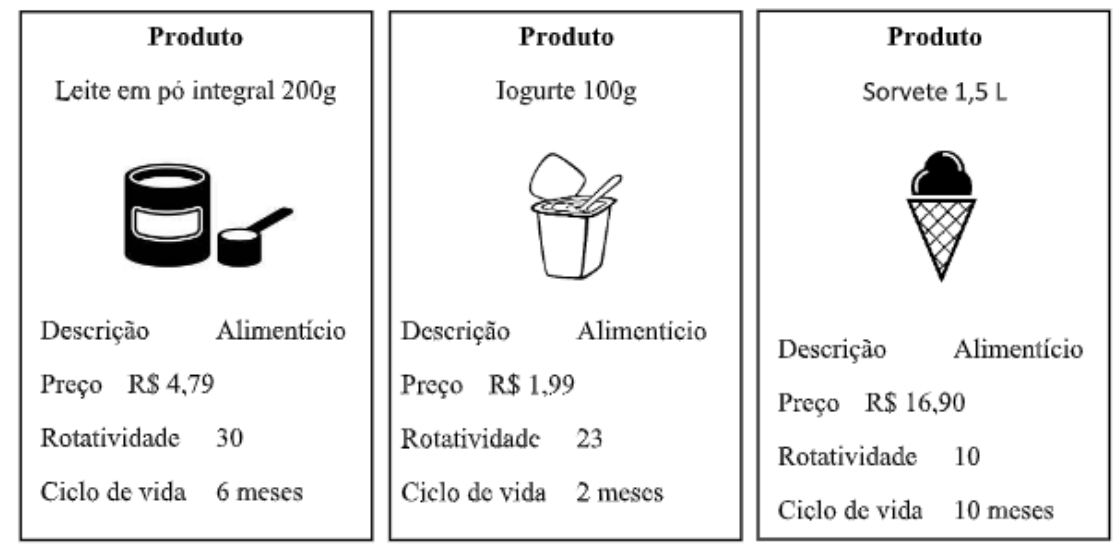

Fonte: Autores (2019).

\section{Conclusão}

O desenvolvimento do jogo Playing With Paretto, transcorreu o seu objetivo de gerar uma conexão entre as estratégias logísticas absorvidas pelo praticante durante o curso, e a adoção moderada da ludicidade. Aplicando-o de maneira correta e produtiva, pode-se reproduzir, sob o ponto de vista do participante, valores necessários para a melhor adaptação e preparação para as variações do mercado, como também, a associação de conceitos logísticos (teórico e práticos) sobre a classificação $\mathrm{ABC}$ e consequentemente da gestão de estoques.

Os jogos quando aplicados como instrumento de ensino aprendizagem apontam ter um significante potencial estratégico, que no contexto atual, torna-se essencial, em virtude da escassez de recursos educacionais imersos nesse cenário tecnocrático competitivo. A fácil adesão de conceitos técnicos somados à prática lúdica garante que a atividade renda tanto em amplitude de conhecimento, como em profundidade.

Sendo assim a produção desse jogo contribui com o pequeno acervo de métodos de ensinamento, a construção de estratégias que resultem em fins eficazes de forma dinâmica. Esse dinamismo oportuniza novas atualizações para desenvolvimento, podendo ser acrescido de novas disciplinas que integrem, propiciando sua utilização em outras áreas.

\section{REFERÊNCIAS}

ADAMO-Villani, N.; Haley-Hermiz, T.; Cutler, R. (2013) “Using a Serious Game Approach to Teach 'Operator Precedence' to Introductory Programming Students”. In: International Conference Information Visualisation IV, p.523-526. 
ARCANJO, F.; CARVALHO, M.; VIEIRA, F. O Papel dos Jogos como Recurso Didático em Programas de Educação Corporativa. In: ENCONTRO DA ASSOCIAÇÃO NACIONAL DE PÓS-GRADUAÇÃ̃O E PESQUISA EM ADMINISTRAÇÃO, 33., 2009, São Paulo. Anais... São Paulo: ANPAD, 2009.

BALLOU, Ronald H. Gerenciamento da Cadeia de Suprimentos-: Logística Empresarial. Bookman Editora, 2009.

BERNARD, R. R. S. Estrutura de utilização dos jogos de empresas nos cursos de graduação em administração e ciências contábeis do país e avaliações preliminares de uma disciplina baseada neste método. In: ENCONTRO NACIONAL DOS CURSOS DE GRADUAÇÃO EM ADMINISTRAÇÃO, 17, 2006, São Luiz. Anais XVII Enangrad. CDROM. 2006.

BORGES, H. Uma classificação sobre a utilização do computador pela escola. Fortaleza, Revista Educação em debate,1999.1 (27): 135-138.

CARLSON, J.; MISSHAUK, M. Introduction to Gaming: Management Decision Simulations. New York: John Wiley \&amp; Sons, 1972.

COUNCIL OF SUPPLY CHAIN MANAGEMENT PROFES-SIONALS (CSCMP). Supply chain and logistics terms and glossary.2013. Disponível em: <http://www.cscmp.org/digital/glossary/document.pdf >. Acesso em: 24/11/2019.

DE CARVALHO, José Mexia Crespo; CARDOSO, Eduardo Gomes. Logística. Sílabo, 2002.

GAITHER, N.; FRAZIER, G. Administração da produção e operações. 8. ed. São Paulo: Pioneira, 2002.

KOPITTKE, B. Simulação empresarial: faça seu jogo. In: ENCONTRO DA ASSOCIAÇÃO NACIONAL DE PÓS-GRADUAÇÃO E PESQUISA EM ADMINISTRAÇÃO, 12., 1989, Belo Horizonte. Anais...Belo Horizonte: ANPAD, 1989.

LAUGENI, Fernando P.; MARTINS, Petrônio G. 3. Ed. - São Paulo: Saraiva, 2015.

logística empresarial. $4^{\mathrm{a}}$ ed. Porto Alegre: Bookmann, 2001.

MIYASHITA, R. Elaboração e uso de um jogo de Logística. Dissertação (Mestrado em Administração) Instituto de Pós-Graduação e Pesquisa em Administração, UFRJ/COPPEAD, Rio de Janeiro, 1997.

ROSAS, André Rosenfeld; SAUAIA, Antonio Carlos Aidar. Jogos de empresas na educação superior no Brasil: perspectivas para 2010. Enfoque: reflexão contábil, v. 25, n. 3, p. 72-85, 2006.

SCHAFRANSKI, A. Jogos de Gestão da Produção: desenvolvimento e validação. Tese (Doutorado em Engenharia de Produção e Sistemas) - Programa de Pós-graduação em Engenharia de Produção e Sistemas, Universidade Federal de Santa Catarina, Florianópolis, 2002.

STONER, James A. F.; FREEMAN, R. Edward. Administração. 5 ed. Rio de Janeiro: Prentice Hall do Brasil, 1999.

SÁ, A. B. P. O.; SILVA, G. M. S.; PEDROSA, M. E. C.; ASSUNÇÃO, M. V. D. LEARNING LAYOUT 1.0: UMA PROPOSTA LÚDICA PARA O DESENVOLVIMENTO DE LAYOUT DE ALMOXARIFADO. In: XXVI Simpósio de Engenharia de Produção em Baurú/SP, 2019. 